\title{
Características quantitativas de carcaça de ovinos Santa Inês confinados alimentados com rações contendo diferentes níveis de caroço de algodão integral
}

\author{
Maria das Graças Gomes Cunha ${ }^{1}$, Francisco Fernando Ramos de Carvalho ${ }^{2}$, Severino \\ Gonzaga Neto ${ }^{3}$, Marcilio Fontes Cezar ${ }^{4}$
}

\author{
${ }^{1}$ Empresa Estadual de Pesquisa Agropecuária da Paraíba. \\ 2 DZ/UFRPE \\ ${ }^{3}$ Departamento de Zootecnia da UFPB. \\ ${ }^{4}$ Departamento Medicina Veterinária da UFCG.
}

RESUMO - Avaliaram-se as características de carcaça, os rendimentos dos cortes e a musculosidade da carcaça de 24 ovinos Santa Inês, inteiros, confinados em baias individuais, alimentados com dietas contendo 0; 20; 30 e 40\% de caroço de algodão integral (CAI). Os animais apresentaram peso corporal inicial médio de 19,5 kg e foram abatidos quando atingiram peso médio de $32,2 \mathrm{~kg}$. Utilizou-se delineamento inteiramente casualizado, com quatro dietas e seis repetições. Não houve efeito para as características quantitativas analisadas em função dos níveis de CAI empregados. O rendimento verdadeiro médio foi de 56,46\%. Para os pesos dos cortes em relação à meia-carcaça, houve efeito linear decrescente para a paleta, enquanto para os rendimentos de cortes não houve efeito dos níveis de CAI. A estimativa de musculosidade da carcaça sofreu efeito linear decrescente para a relação músculo:osso e área de olho-de-lombo. Entre os tecidos constituintes da perna, a porcentagem de músculo sofreu influência decrescente. Os níveis de CAI proporcionaram menor musculosidade da carcaça, sem, no entanto, afetar as características e o rendimento de cortes da carcaça de cordeiros Santa Inês, podendo ser incluído em dietas de terminação.

Palavras-chave: cortes comerciais, gossipol, musculosidade, peso corporal, rendimento de carcaça

\section{Effect of feeding whole cottonseed levels on carcass quantitative characteristics of feedlot Santa Inez sheep}

ABSTRACT - This work was carried out with the objective to evaluate the effects of different levels $(0.020 .0,30.0$ and $40.0 \%$ ) of whole cottonseed (Gossypium hirsutum L.) of the diet (\% DM) on carcass characteristics, cut yields and carcass muscularity of feedlot Santa Inez sheep. Twenty-four sheep with average initial and final body weight of 19.0 and $32,2 \mathrm{~kg}$, respectively, and allotted to a completely randomized design, with four diets and six replications. No effect was observed for the inclusion of whole cottonseed (WCS) levels to the diets on quantitative characteristics. The average true carcass dressing yield was $56.46 \%$. For the cuts weights based on half carcass, there was a decreasing linear effect for shoulder, while for the cut yields there was not effect of the inclusion of WCS levels in the diet. The estimated of carcass muscularity index presented decreasing linear effect for the muscle:bone ratio and loin eye area. Among the tissues that compose the leg, the muscle percentage a decreasing linear effect was observed. The levels of whole cottonseed provided smaller carcass muscularity, without however affect characteristics and yields of carcass cuts the Santa Inez lambs and could be included in termination diets.

Key Words: commercial cuts, gossypol, muscularity, body weight, carcass dressing

\section{Introdução}

No Brasil, verifica-se nos últimos anos aumento significativo na demanda de carne ovina, principalmente nos grandes centros urbanos, o que tem impulsionado a produção de animais para abate, levando à expansão da ovinocultura. A produção de carne depende, em grande parte, do processo de crescimento, uma vez que a carne resulta do crescimento dos tecidos corporais. Vários são os fatores que influenciam a composição tecidual e, conseqüentemente, o crescimento animal, com destaque para a nutrição, tendo em vista que a produtividade é influenciada pela qualidade e quantidade de nutrientes consumidos. O nível nutricional a que o animal está submetido exerce grande influência sobre o rendimento da carcaça e de seus cortes e a proporção dos tecidos musculares. 
Os ovinos apresentam características produtivas diferentes dos bovinos: melhor qualidade de carne, maiores rendimentos de carcaça e eficiência de produção decorrente de sua alta velocidade de crescimento, as quais devem ser valorizadas para maximizar a produção de carne. Entretanto, no Brasil e especialmente no Nordeste, a produção e comercialização da carne ovina ainda encontram-se desorganizadas, apresentando baixa oferta, prejudicando, conseqüentemente, o crescimento no consumo.

Segundo dados do IBGE (2006), o Nordeste possui efetivo ovino de aproximadamente 8.712.000 animais, representando $57,86 \%$ do rebanho nacional. Esse rebanho é composto, na maioria, por animais deslanados e semilanados, sendo os sem raça definida a grande maioria, seguidos das raças Santa Inês, Morada Nova e Somalis Brasileira (Cezar, 2004).

O confinamento de ovinos tem despertado interesse de muitos criadores como alternativa para melhorar o sistema de produção, visando manter a regularidade na oferta de carne e peles durante $\mathrm{o}$ ano para atender o mercado nacional (Medeiros, 2006).

A qualidade da carne está relacionada à saúde e preferência do consumidor e pode ser afetada por diferentes fatores como alimentação, idade, peso de abate, sexo e genótipo. O peso e idade de abate ideais variam muito entre as raças ovinas; no entanto, deve-se procurar abater animais jovens, com características de carcaça que atendam às exigências do consumidor, pois, com o avançar da idade, o animal tende a depositar menor quantidade de proteína, enquanto a de lipídio aumenta (Macedo et al., 2000). O rendimento de carcaça é uma característica diretamente relacionada à produção de carne e pode variar de acordo com fatores intrínsecos e/ou extrínsecos ao animal.

Com a maior procura por alimentos para compor as rações formuladas para as diversas categorias animais da ovinocultura, cresce a demanda por aqueles que permitam bom desempenho animal e economia nos sistemas intensivos de produção. Em função disso, a utilização de alimentos alternativos tem se destacado como bons componentes energéticos para ração de ruminantes.

O caroço de algodão é uma ótima alternativa para o uso em confinamento de ruminantes, por ser um alimento com proteína de alto valor biológico e teor de energia, facilitando a formulação de dietas de custo mínimo. Outra vantagem seria que a gordura contida na carne produzida poderia ter um perfil mais insaturado, em razão de grande parte da energia desse alimento estar na forma de gordura, promovendo menor incremento calórico e resultando em melhor conversão alimentar (Medeiros et al., 2005).
Objetivou-se, com este trabalho, avaliar o efeito de dietas contendo diferentes níveis de caroço de algodão integral sobre as características quantitativas da carcaça e dos cortes de ovinos Santa Inês.

\section{Material e Métodos}

A pesquisa foi conduzida na Estação Experimental Pendência da Empresa Estadual de Pesquisa Agropecuária da Paraíba, na microrregião do cariri paraibano, no município de Soledade - PB, situado a 78'18" S, 36²7' 2"W.Gr, com altitude em torno de $534 \mathrm{~m}$, temperatura média ao longo do ano de $30^{\circ} \mathrm{C}$ e umidade relativa do ar de $68 \%$. O clima da região é classificado como semi-árido quente, de 7 a 8 meses secos, com chuvas de verão, e precipitação média anual de 350 a $600 \mathrm{~mm} / \mathrm{ano}$.

O caroço de algodão utilizado nesta pesquisa foi proveniente da fazenda Mizote - São Desidério - estado da Bahia, caracterizado como tipo comercial “caroço de algodão branco”, com alto conteúdo de fibra, adquirido junto ao comércio local, assim como o milho, a soja e minerais. O feno de Tifton-85 (Cynodon spp), adquirido junto à Agropecuária Laranjeiras, no Rio Grande do Norte, e a palma forrageira (Opuntia fícus indica Mill), cultivar gigante, foi fornecida pela Estação Experimental Pendência -Emepa - PB.

Foram utilizados 24 cordeiros inteiros da raça Santa Inês, com peso corporal médio inicial de 19,5 kg e quatro meses de idade, distribuídos ao acaso às dietas experimentais com quatro dietas e seis repetições. Após realização das medidas sanitárias, os animais foram alojados em baias individuais $(0,80 \times 1,20 \mathrm{~m})$ providas de comedouros e bebedouros, dispostas em um galpão de alvenaria. O período experimental (70 dias) foi precedido de 14 dias para adaptação ao manejo e às dietas. As pesagens dos animais ocorreram a cada 14 dias a partir do início do experimento.

As dietas (Tabela 1) foram formuladas com a inclusão de níveis crescentes (0, 20, 30 e 40\%) de caroço de algodão integral, com base na matéria seca, e constituídas de palma forrageira, feno de Tifton-85, milho triturado, farelo de soja, uréia e minerais, balanceadas segundo NRC (1985), visando atender às exigências de proteína e energia metabolizável dos animais para ganho de peso médio diário de $150 \mathrm{~g}$. A ração foi fornecida com base em 5\% do peso corporal, distribuída em duas refeições diárias, às 8 e 16 h, e as sobras existentes foram pesadas e registradas na manhã do dia seguinte. Amostras das dietas e sobras foram coletadas semanalmente, processadas e armazenadas para posteriores análises, realizadas no laboratório de Nutrição Animal da Universidade Federal da Paraíba. 
Tabela 1 - Composições em ingrediente e nutricional das dietas experimentais, \% MS

\begin{tabular}{|c|c|c|c|c|}
\hline $\begin{array}{l}\text { Item } \\
\text { Ingrediente, \% MS }\end{array}$ & \multicolumn{4}{|c|}{ Nível de caroço de algodão (\%) } \\
\hline Feno de capim Tifton 85 & 33,10 & 30,50 & 36,60 & 31,20 \\
\hline Farelo de soja & 7,80 & - & - & - \\
\hline Caroço de algodão & 0 & 20,00 & 30,00 & 40,00 \\
\hline Palma forrageira & 24,40 & 25,00 & 25,20 & 25,80 \\
\hline Mistura mineral ${ }^{1}$ & 0,50 & 0,50 & 0,50 & 0,50 \\
\hline \multicolumn{5}{|l|}{ Composição nutricional } \\
\hline Matéria seca (\%) & 31,40 & 30,90 & 30,80 & 30,30 \\
\hline Proteína bruta (\%) & 15,00 & 15,00 & 15,90 & 16,70 \\
\hline Extrato etéreo (\%) & 2,90 & 6,00 & 7,40 & 9,00 \\
\hline Matéria mineral (\%) & 6,90 & 7,40 & 6,60 & 8,10 \\
\hline Nutrientes digestíveis totais (\%) & 66,10 & 66,72 & 65,50 & 66,43 \\
\hline Energia metabolizável, Mcal de EM/kg de MS & 2,39 & 2,40 & 2,37 & 2,40 \\
\hline
\end{tabular}

${ }^{1}$ Níveis de garantia (nutrientes $/ \mathrm{kg}$ ): cálcio $130 \mathrm{~g}$; fósforo $70 \mathrm{~g}$; magnésio $1.320 \mathrm{mg}$; ferro $2.200 \mathrm{mg}$; cobalto $140 \mathrm{mg}$; manganês $3,690 \mathrm{mg}$; zinco $4.700 \mathrm{mg}$ : iodo $61 \mathrm{mg}$; selênio $45 \mathrm{mg}$; enxofre $12 \mathrm{~g}$; sódio $170 \mathrm{~g}$; cloro $276 \mathrm{~g}$; flúor máximo $700 \mathrm{mg}$; solubilidade mínima de $\mathrm{P}_{2} \mathrm{O}_{5}$ em ácido cítrico a $2 \%=90 \%$.

Ao final do período experimental, os animais foram pesados, obtendo-se assim o peso corporal final (PCF), e submetidos ao jejum alimentar por 18 horas, quando foram novamente pesados para obtenção do peso de abate (PCA), objetivando a determinação do percentual de perda de peso decorrente do jejum (PJ), que foi calculada pela fórmula: PJ (\%) = (PC-PCA) x 100/PCA. No momento do abate, os animais foram insensibilizados por atordoamento na região atla-occipital, seguida de sangria através da secção das carótidas e jugular, de modo que o sangue recolhido em balde (previamente tarado) foi imediatamente. Após o abate, o conteúdo do trato gastrintestinal foi retirado para determinação do peso do corpo vazio (PCV) e do rendimento verdadeiro, representado pela seguinte fórmula: RV (\%) = peso da carcaça quente PCQ/PCV x 100. As determinações das características quantitativas das carcaças foram realizadas segundo metodologia descrita por Silva Sobrinho (2001).

Após a evisceração e retirada dos constituintes nãocarcaça, foi obtido o peso da carcaça quente (PCQ). Todos os constituintes não-carcaça foram lavados e pesados separadamente. As carcaças foram acondicionadas em sacos plásticos e transportadas para uma câmara frigorífica a $4^{\circ} \mathrm{C}$, onde permaneceram suspensas pelos tendões da perna por 24 horas. Ao final desse período, foram pesadas para determinação do peso da carcaça fria, calculando-se então a perda por resfriamento (PR), em que PR $(\%)=(P C Q-P C F)$ $\mathrm{x}$ 100/PCQ. Em seguida, foram retirados rins e gorduras renal e pélvica, que foram subtraídas das carcaças quente e fria, quando então foi calculado o rendimento de carcaça quente (RCQ, \%), que é representado por PCQ/PVA x 100, e de carcaça fria (RCF, \%= PCF/PVA x 100).

A musculosidade da carcaça foi estimada de forma indireta, na qual, em vez de realizar a separação dos ossos, músculos e gorduras na carcaça inteira, foram utilizados três outros parâmetros que apresentam altas correlações: índice de musculosidade da perna, relação músculo/osso da perna e área de olho-de-lombo (AOL).

Na meia-carcaça direita, realizou-se um corte transversal entre $12^{\mathrm{a}}$ e $13^{\mathrm{a}}$ costelas, expondo a secção transversal do músculo Longissimus dorsi, cuja área foi tracejada, por meio de caneta apropriada, sobre uma película plástica transparente para determinação da AOL. Para tanto, foram obtidas, por meio de régua, a largura máxima (A) e a profundidade máxima (B) para serem utilizadas pela fórmula: $\mathrm{AOL}=(\mathrm{A} / 2 * \mathrm{~B} / 2) \pi$, segundo Silva Sobrinho (1999) e, assim, determinar sua área.

A espessura de gordura de lombo (EGL) foi medida com um paquímetro, obtida a 3/4 de distância a partir do lado medial do músculo Longissimus dorsi, para o seu lado lateral da linha dorso-lombar. O índice de musculosidade da perna dos cordeiros foi estimado pela dissecação dos tecidos da perna. A perna, após ter sido pesada, foi acondicionada em saco plástico e congelada em freezer $\left(-20^{\circ} \mathrm{C}\right)$. Posteriormente, foi feita a separação dos tecidos muscular, ósseo e adiposo e, em seguida, a medição do osso do fêmur 
para o cálculo do índice de musculosidade da perna, segundo a metodologia descrita por Purchas et al. (1991).

$$
I M P=\frac{\sqrt{P 5 M / C F}}{C F}
$$

em que: $\mathrm{IM}$ = índice de musculosidade da perna; P5M = peso dos cinco músculos (bíceps femural, quadríceps femural, semimembranoso, semitendinoso e adutor), em g; CF = comprimento do fêmur, em cm.

A meia-carcaça direita foi subdividida em seis regiões anatômicas, as quais foram pesadas individualmente (pescoço, perna, paleta, lombo, costilhar e serrote) para determinação das porcentagens em relação à carcaça inteira, segundo metodologia proposta pela Embrapa (1994).

Foram obtidos os seguintes cortes: pescoço - constitui a região compreendida entre a $1^{\mathrm{a}}$ e $7^{\mathrm{a}}$ vértebras cervicais; paleta - região obtida pela desarticulação da escápula; costilhar - compreende a seção entre a $1^{\mathrm{a}}$ e $13^{\mathrm{a}}$ vértebra torácicas; lombo - entre a $1^{\mathrm{a}}$ e $6^{\mathrm{a}}$ vértebras lombares; perna - obtida pela secção entre a ultima vértebra lombar e a primeira sacra; e serrote - obtido pelo corte em linha reta, iniciando-se no flanco até a extremidade cranial do manúbrio do esterno.

O delineamento experimental adotado foi inteiramente casualizado, com quatro tratamentos e seis repetições, fazendo-se a interpretação estatística dos resultados por meio de análises de variância e regressão, em função dos níveis de CAI na dieta. As análises foram realizadas com o auxílio do programa Statistical Analysis System (SAS, 1999).

\section{Resultados e Discussão}

Não houve influência dos níveis de CAI $(\mathrm{P}>0,05)$ sobre as características PCV, PCQ, PCF, RCQ e RCF, cujas médias foram de 27,17; 15,35; 15,02 kg; 47,64 e 46,60\%, respectiva- mente (Tabela 2); no entanto, observou-se decréscimo com a inclusão do CAI. Santos et al. (2006) obtiveram valores de 46,28 e 45,70\% para rendimentos de carcaça quente e fria em ovinos Santa Inês terminados com dieta à base de granola em grãos e seus subprodutos.

O peso corporal está altamente correlacionado com o peso da carcaça, conforme observaram Martins et al. (2000), em cordeiros, 96,04\% da variação no peso da carcaça decorreram da variação no peso corporal. Garcia et al. (2000) obtiveram RCQ de 53,1\% em cordeiros Santa Inês confinados, enquanto Santos (1999), RCQ de 48,0\% e RCF de $47 \%$ em ovinos Santa Inês recebendo $80 \%$ de concentrado.

Resultados similares ao desta pesquisa foram obtidos por Urano et al. (2006), que alimentaram cordeiros Santa Inês com níveis crescentes de grão de soja na dieta e não verificaram diferenças para as variáveis RCQ, RCF e PR, com médias de 48,9; 47,7 e 2,4\%, respectivamente. Também Moletta et al. (1999) utilizaram CAI na terminação de bovinos de corte e não observaram influência desse alimento sobre as características de carcaça.

Kandylis et al. (1998) observaram que cordeiros Karagouniko alimentados com níveis crescentes de caroço de algodão (5, 10, 15, 20 e 30\%) na dieta, abatidos com $30 \mathrm{~kg}$ de peso corporal, não apresentaram diferenças entre os tratamentos para os RCQ e RCF, sendo as médias de 48,2 e $46,7 \%$, respectivamente, similares aos resultados obtidos neste estudo.

A perda por resfriamento expressa a diferença de peso após o resfriamento da carcaça, estando em função, principalmente, da quantidade de gordura de cobertura e da perda de umidade. As perdas de peso por resfriamento (PR) variaram de 1,47 a 2,45\%, com média de 2,10\%, valores considerados normais de acordo com Osório et al. (1999) e Cartaxo (2006).

Tabela 2 - Características de carcaça de ovinos Santa Inês alimentados com diferentes níveis de caroço de algodão integral na dieta

\begin{tabular}{|c|c|c|c|c|c|c|c|}
\hline \multirow[t]{2}{*}{ Item } & \multicolumn{4}{|c|}{ Nível de caroço de algodão integral (\%) } & \multirow[b]{2}{*}{ Regressão } & \multirow[b]{2}{*}{$\mathrm{R}^{2}$} & \multirow[b]{2}{*}{ CV (\%) } \\
\hline & 0 & 20 & 30 & 40 & & & \\
\hline Peso corporal abate, kg & 33,50 & 32,66 & 30,41 & 32,16 & $\hat{\mathrm{Y}}=32,18$ & - & 6,28 \\
\hline Peso do corpo vazio, kg & 28,22 & 27,57 & 26,02 & 26,86 & $\hat{\mathrm{Y}}=27,17$ & - & 7,10 \\
\hline Conteúdo do TGI, kg & 5,27 & 5,10 & 4,40 & 5,30 & $\hat{\mathrm{Y}}=5,01$ & - & 21,66 \\
\hline Rend. de carcaça quente, \% & 48,80 & 47,38 & 47,31 & 47,05 & $\hat{\mathrm{Y}}=47,64$ & - & 4,08 \\
\hline Rend. de carcaça fria, \% & 47,58 & 46,65 & 46,28 & 45,90 & $\hat{\mathrm{Y}}=46,60$ & - & 3,81 \\
\hline Rend. verdadeiro \% & 57,87 & 56,07 & 55,48 & 56,40 & $\hat{\mathrm{Y}}=56,46$ & - & 4,27 \\
\hline Perda por resfriamento, \% & 2,45 & 1,47 & 2,07 & 2,41 & $\hat{\mathrm{Y}}=2,10$ & - & 36,37 \\
\hline
\end{tabular}

$\mathrm{TGI}=$ trato gastrointestinal. 
Segundo Martins et al. (2000), em ovinos, de forma geral, os índices de perda por resfriamento estão em torno de $2,5 \%$, podendo ocorrer oscilação entre 1 e $7 \%$, de acordo com a uniformidade da cobertura de gordura, o sexo, peso, temperatura e umidade relativa da câmara fria. Contudo, as perdas por resfriamento observadas neste estudo foram menores que as de 2,92 e 2,96\% citadas por Neres et al. (2001), em cordeiros com peso de carcaça quente variando de 13,17 a 13,45 kg, respectivamente, que as de 4,91; 3,04; 4,30 e 3,34\% observadas por Siqueira et al. (2001), em cordeiros abatidos com pesos corporais de 28, 32, 36 e $40 \mathrm{~kg}$, respectivamente; e a média obtida por Motta et al. (2001), de $4,86 \%$, avaliando cordeiros com peso de carcaça quente $13,41 \mathrm{~kg}$. Provavelmente, as menores perdas verificadas nessa pesquisa decorreram do envolvimento das carcaças em sacos plásticos durante o período de resfriamento.

Para o rendimento verdadeiro, os valores observados foram de 57,$87 ; 56,07 ; 55,48$ e $56,40 \%$. Observa-se que não houve influência do nível de CAI sobre esta variável, sendo estes valores superiores aos encontrados por Cartaxo (2006), em ovinos Santa Inês alimentados com $40 \%$ de feno de maniçoba na dieta e abatidos em duas condições corporais: média (48,16\%) e gorda $(49,71 \%)$. Valores semelhantes aos deste estudo foram relatados por Santos et al. (2006), que obtiveram 56,19\% em cordeiros Santa Inês alimentados com grãos e subprodutos da granola. Também Alves et al. (2003), avaliando características de carcaça de ovinos Santa Inês com pesos de abate semelhantes aos deste estudo, obtiveram rendi- mento médio de 55,28\%; portanto, similares aos destes ensaios.

Os valores apresentados na Tabela 3 mostram que não houve efeito dos níveis de caroço de algodão na dieta, com exceção da paleta, que apresentou efeito linear decrescente ( $\mathrm{P}<0,01$ ), embora tenha ocorrido superioridade da dieta controle em relação às demais.

Estes resultados podem ser atribuídos ao fato de os animais terem sido abatidos com pesos corporais semelhantes, o que corrobora as inferências de Osório (2002) de que, quando as carcaças apresentam pesos e quantidade de gordura semelhantes, quase todas as regiões do corpo têm proporções similares, independentemente da raça. Os valores observados neste estudo estão próximos dos verificados por Frescura et al. (2003), que testaram diferentes sistemas alimentares na terminação de cordeiros Ile de France $\times$ Texel, obtendo valores médios de 33,31\% para perna, 19,17\% para paleta e $9,05 \%$ para pescoço. Os valores obtidos para peso de paleta neste estudo estão em conformidade com os obtidos por Rosa et al. (2002) e Osório et al. (2002), que constataram crescimento muscular precoce na paleta em relação aos demais componentes da carcaça.

De acordo com Pilar (2002), os distintos cortes que compõem a carcaça possuem diferentes valores econômicos e sua proporção constitui um importante índice para a avaliação comercial da carcaça. Entretanto, a literatura aponta grande variação nesses valores em função de fatores como genética, sexo, peso corporal, tipo de dieta e número de horas em jejum.

Tabela 3 - Pesos da meia-carcaça e dos cortes comerciais da carcaça de ovinos Santa Inês alimentados com diferentes níveis de caroço de algodão integral na dieta

\begin{tabular}{|c|c|c|c|c|c|c|c|}
\hline \multirow[t]{2}{*}{ Peso dos cortes $(\mathrm{kg})$} & \multicolumn{4}{|c|}{ Nível de caroço de algodão integral (\%) } & \multirow[b]{2}{*}{ Regressão } & \multirow[b]{2}{*}{$\mathrm{R}^{2}$} & \multirow[b]{2}{*}{ CV (\%) } \\
\hline & 0 & 20 & 30 & 40 & & & \\
\hline Peso da meia-carcaça fria $(\mathrm{kg})$ & 7,65 & 7,25 & 6,68 & 7,08 & $\hat{\mathrm{Y}}=7,16$ & - & 8,57 \\
\hline Perna (kg) & 2,460 & 2,270 & 2,140 & 2,180 & $\hat{\mathrm{Y}}=2,27$ & - & 8,77 \\
\hline Paleta (kg) & 1,530 & 1,390 & 1,340 & 1,360 & $\hat{\mathrm{Y}}=1,5116-0,0047^{* *} \mathrm{X}$ & 0,83 & 7,87 \\
\hline Lombo (kg) & 0,775 & 0,793 & 0,733 & 0,745 & $\hat{\mathrm{Y}}=0,761$ & - & 12,07 \\
\hline Costilhar (kg) & 1,350 & 1,225 & 1,233 & 1,182 & $\hat{\mathrm{Y}}=1,247$ & - & 16,0 \\
\hline Serrote (kg) & 0,893 & 0,901 & 0,772 & 0,847 & $\hat{\mathrm{Y}}=0,854$ & - & 10,15 \\
\hline Pescoço (kg) & 0,615 & 0,575 & 0,473 & 0,520 & $\hat{\mathrm{Y}}=0,545$ & - & 18,60 \\
\hline \multicolumn{8}{|l|}{ Rendimento dos cortes (\%) } \\
\hline Perna (\%) & 32,16 & 31,41 & 32,14 & 30,81 & $\hat{\mathrm{Y}}=31,63$ & - & 3,67 \\
\hline Paleta (\%) & 20,0 & 19,3 & 21,7 & 19,3 & $\hat{\mathrm{Y}}=20,0$ & - & 4,98 \\
\hline Lombo (\%) & 10,20 & 10,92 & 10,96 & 10,51 & $\hat{\mathrm{Y}}=10,65$ & - & 9,72 \\
\hline Pescoço (\%) & 8,07 & 7,92 & 7,12 & 7,32 & $\hat{\mathrm{Y}}=7,61$ & - & 17,21 \\
\hline Costilhar (\%) & 17,60 & 16,81 & 18,31 & 16,73 & $\hat{\mathrm{Y}}=17,36$ & - & 7,72 \\
\hline Serrote (\%) & 11,70 & 12,43 & 11,54 & 11,97 & $\hat{\mathrm{Y}}=11,91$ & - & 6,26 \\
\hline
\end{tabular}

** Significativo a $1 \%$ de probabilidade pelo teste $\mathrm{F}$. 
Entre as variáveis analisadas, a perna apresentou maior rendimento (32,16; 31,14; 32,14 e 30,81\%) em relação à meiacarcaça, mas não sofreu influência dos níveis do CAI testados, em razão de ser o corte com maior musculosidade, seguido da paleta (20,0; 19,3; 21,7 e 19,3\%). Estes resultados evidenciam o efeito da dieta, principalmente do nível de energia na dieta (Tabela 1).

Resultados similares foram obtidos por Alves et al. (2003), com ovinos Santa Inês para os cortes lombo e paleta, e Medeiros (2006), com ovinos Morada Nova para perna, costelas, paleta e lombo. Furusho-Garcia et al. (2003) também não constataram diferenças significativas em ovinos Santa Inês e outros grupos genéticos para os pesos de perna e lombo, o que pode ser explicado pela maior quantidade de tecido muscular desses cortes, quando comparados aos demais. Yamamoto et al. (2004) incluíram fontes de gordura em rações de cordeiros Santa Inês e mestiços Santa Inês $\times$ Dorset abatidos com 30 kg e não observaram diferenças no rendimento dos cortes perna, paleta e lombo em relação à dieta controle, com médias de 35,5; 18,8 e 9,3\% do PCF, respectivamente.

Os valores observados neste estudo estão próximos aos verificados por Frescura et al. (2003), que testaram diferentes sistemas de alimentação na terminação de cordeiros Ile de France × Texel e obtiveram médias de 33,31\% para perna, $19,17 \%$ para paleta e $9,05 \%$ para pescoço. Os cortes considerados nobres, perna e lombo, em relação à meia-carcaça, representaram, em média, 42,2\% do valor comercial da carcaça.

Tão importante quanto a composição regional da carcaça é sua composição tecidual, pois a carcaça, através de seus diversos cortes comerciais, apresenta partes comestíveis e não-comestíveis, sendo que, entre as não-comestíveis, os ossos perfazem a maior parte. O excesso de gordura, embora comestível, é de pequeno valor comercial e, em determinados casos, indesejável. Muitos métodos foram desenvolvidos para estimar a composição da carcaça; embora a separação física completa da carcaça seja um dos mais precisos, tem a desvantagem de ser laboriosa. Todavia, alguns métodos como medida da AOL, índice de musculosidade da perna, relação músculo:osso da perna e composição tecidual de determinado corte da carcaça, como a perna e paleta, têm demonstrado boas estimativas da composição tecidual das carcaças ovinas (Cezar, 2004).

Os músculos de maturidade tardia são indicados para representar o desenvolvimento e tamanho do tecido muscular, e o Longissimus dorsi, cuja medição é conhecida como AOL, é o mais indicado, pois apresenta amadurecimento tardio e é de fácil mensuração (Sainz, 1996).

A medida da AOL realizada no músculo Longissimus tem se mostrado diretamente ligada ao total de músculos na carcaça, enquanto a espessura de gordura subcutânea, diretamente ao total de gordura na carcaça e indiretamente à quantidade de músculos, uma vez que, quanto maior o acúmulo de gordura, menor a proporção de músculos (Forrest et al., 1975). Foi observado efeito linear decrescente $(\mathrm{P}<0,01)$ para a AOL; a equação de regressão mostra que houve decréscimo de $0,063 \mathrm{~cm}^{2}$ para cada unidade de aumento no nível de caroço de algodão na dieta. Este também foi observado para a relação músculo:gordura, que apresentou efeito linear decrescente $(\mathrm{P}<0,05)$, podendo-se inferir que o tipo de gordura do CAI não promoveu deposição de tecido gorduroso na carcaça (Tabela 4).

Brito (2002) encontrou AOL de 11,1 cm² e EG de 1,8 m, em cordeiros Santa Inês com peso corporal de 30,0 kg, e carcaça fria de 13,74 kg. Siqueira \& Fernandes (2001) verificaram, em ovinos terminados em confinamento abatidos com 30 e $32 \mathrm{~kg}$, valores de 8,51 e 9,44cm², próximos aos deste

Tabela 4 - Composição tecidual da carcaça de ovinos Santa Inês, em função de diferentes níveis de caroço de algodão integral na dieta

\begin{tabular}{|c|c|c|c|c|c|c|c|}
\hline Musculosidade da carcaça & \multicolumn{4}{|c|}{ Nível de caroço de algodão integral (\%) } & Regressão & $\mathrm{R}^{2}$ & CV (\%) \\
\hline Relação músculo:osso & 6,17 & 5,52 & 5,27 & 4,99 & $\hat{\mathrm{Y}}=6,153-0,0295^{* *} \mathrm{X}$ & 0,89 & 9,32 \\
\hline Relação músculo:gordura & 13,20 & 8,72 & 8,77 & 7,88 & $\hat{\mathrm{Y}}=12,811-0,0475^{*} \mathrm{X}$ & 0,83 & 8,20 \\
\hline Índice de musculosidade da perna & 0,30 & 0,27 & 0,29 & 0,28 & $\hat{Y}=0,28$ & - & 7,14 \\
\hline Área de olho-de-lombo $\left(\mathrm{cm}^{2}\right)$ & 11,30 & 9,22 & 9,52 & 8,60 & $\hat{\mathrm{Y}}=11,0662-0,063^{* *} \mathrm{X}$ & 0,87 & 13,70 \\
\hline Músculo & 67,10 & 63,51 & 64,02 & 62,23 & $\hat{\mathrm{Y}}=66,770-0,1135^{* *} \mathrm{X}$ & 0,88 & 3,10 \\
\hline Osso & 23,08 & 24,03 & 25,07 & 24,92 & $\hat{\mathrm{Y}}=24,3$ & - & 6,11 \\
\hline Gordura & 5,13 & 7,30 & 7,30 & 7,90 & $\hat{\mathrm{Y}}=6,90$ & - & 24,6 \\
\hline Outros+ & 4,70 & 5,10 & 3,60 & 4,90 & $\hat{\mathrm{Y}}=4,60$ & - & 41,3 \\
\hline
\end{tabular}

+Outros: vasos sangüíneos, nervos e tendões.

** Significativo a $1 \%$ de probabilidade pelo teste $\mathrm{F}$. 
ensaio, que variaram de 8,6 a $11,2 \mathrm{~cm}^{2}$, com a dieta controle apresentando valor superior em relação às demais. Urano et al. (2006) obtiveram valores de $14,8 \mathrm{~cm}^{2}$ e $1,5 \mathrm{~mm}$ para AOL e EG, respectivamente, em cordeiros Santa Inês alimentados com níveis crescentes de soja grão; portanto, superiores aos deste trabalho.

Em termos absolutos, os cordeiros que receberam as dietas com CAI apresentaram maiores proporções de osso e gordura na perna que os alimentados com a dieta controle, ao passo que, para as carcaças as relações músculo:gordura, o efeito foi linear decrescente.

A gordura de cobertura, utilizada como medida de acabamento externo, quando em excesso, pode ser restritiva na escolha do consumidor; por ser uma medida subjetiva, depende muito dos avaliadores, o que por vezes torna complicada a comparação entre os trabalhos. O valor médio para esta variável obtido neste trabalho foi de $1,1 \mathrm{~mm}$, podendo ser considerado baixo, não proporcionando boa cobertura de gordura nas carcaças, motivo pelo qual foram protegidas com sacos plásticos no processo de resfriamento, uma vez que a escassez dessa gordura promove a desidratação da carcaça e o escurecimento dos músculos.

De acordo com a classificação Silva Sobrinho (2001), as carcaças utilizadas nesta pesquisa apresentaram gordura escassa (que variam de 1 a $2 \mathrm{~mm}$ de espessura), média de $1,1 \mathrm{~mm}$, podendo estar relacionada à idade dos animais ou ao processo de retirada do couro; provavelmente parte dessa gordura tenha sido removida com a pele. Resultado semelhante foi obtido por Santos et al. (2006), em ovinos Santa Inês alimentados com grãos e subprodutos da granola.

A gordura proveniente da ração tende a promover sua deposição na carcaça do animal, porém apresenta grande variação, podendo ser influenciada pelo tipo de gordura, consumo, estado fisiológico e pela categoria animal. Neste ensaio, devido ao fato de os animais estarem em fase de crescimento, ao tipo de gordura da dieta ou ao curto período de confinamento, não houve deposição desse tecido na carcaça. Huerta-Leidenz et al. (1991) e Aferri et al. (2005) utilizaram gordura protegida na forma de caroço de algodão, na terminação de bovinos, e também não verificaram influência do CAI sobre a espessura de gordura de cobertura. Ngidi et al. (1990) observaram que o uso da gordura protegida não afetou a EG nas carcaças, independentemente dos pesos das mesmas.

Segundo Rosa et al. (2002), o crescimento do tecido muscular é caracterizado, até o momento antes do nascimento, pelo aumento do número de células e, após o nascimento, pelo aumento do tamanho das células. Em carcaças de cordeiros Santa Inês abatidos em diferentes condições corporais, Cartaxo (2006) encontrou valores de índice de musculosidade de 0,$32 ; 0,38$ e 0,40 , respectivamente, para as condições magra, média e gorda, valores superiores aos verificados nesta pesquisa, cujas médias foram de 0,30 ; 0,27; 0,29 e 0,28, respectivamente, para os níveis crescentes de CAI (Tabela 4). Estes resultados estão de acordo com as afirmações de Silva Sobrinho et al. (2005), que preconizam que as medidas de musculosidade da perna podem não diferir, mesmo quando há diferenças na quantidade de músculos, decorrentes das variações no comprimento do osso por causa da idade dentro de uma mesma raça.

Alguns trabalhos, como os de Abdullah et al. (1998) e Silva \& Portugal (2001), indicaram o índice de muscularidade da perna como alternativa para estimar a composição tecidual da carcaça. Segundo Purchas et al. (1991) e Abdullah et al. (1998), a musculosidade da perna uma medida correlacionada à deposição de gordura e à relação músculo:osso - pode variar em decorrência de fatores genéticos e ambientais como idade, raça, peso corporal e dieta.

A separação física dos componentes da carcaça avaliada pela perna mostrou que os animais alimentados com CAI apresentaram menor porcentagem de músculos em ao que receberam a dieta controle e semelhante de osso e gordura entre as dietas. A estimativa da musculosidade da carcaça sofreu influência decrescente $(\mathrm{P}<0,01)$ dos níveis de caroço de algodão para a relação músculo:osso e AOL.

Em ordem de prioridade, os tecidos que se acumulam, de acordo com a maturidade fisiológica, são o ósseo, o muscular e o adiposo. Os resultados de pesquisas (Santos et al., 2001; Rosa et al., 2002; Silva \& Pires, 2000) têm mostrado desenvolvimento precoce do tecido ósseo, tardio do tecido adiposo e intermediário do tecido muscular. A relação músculo:osso decresceu na proporção de 0,0295 para cada unidade de aumento do algodão na dieta, sendo a menor observada na dieta com $40 \%$, contudo, a gordura de cobertura que está relacionada ao total da gordura na carcaça não foi afetada pelo tipo de alimento utilizado.

Em relação aos tecidos constituintes da perna, apenas o músculo foi influenciado pelos níveis de caroço de algodão, apresentando efeito linear decrescente $(P<0,05)$ em relação aos demais. Os valores médios de 64,22; 24,28; 6,90 e $4,57 \%$, para músculo, osso, gordura e outros tecidos, respectivamente, encontrados neste estudo, foram similares aos de Osório et al. (1999), que observaram, na perna de cordeiros mestiços Hampshire Down $\times$ Corriedale abatidos aos 150 dias de idade com 30,6 kg, proporção média de $69,10 \%$ de músculo, $24,10 \%$ de gordura e $6,67 \%$ para gordura. De acordo com Santos et al. (2001), entre os 
tecidos que constituem a carcaça, destacam-se os músculos, a gordura e os ossos, sendo que o tecido muscular é o mais importante por apresentar valor comercial.

A quantidade relativa de músculo sofreu influência das dietas experimentais, enquanto as proporções de osso, gordura e outros tecidos na perna não foram afetadas $(\mathrm{P}<0,05)$ pela dieta fornecida. Apesar de não haver efeito entre as dietas para as quantidades relativas de osso e gordura nos animais que consumiram caroço de algodão, houve tendência de aumento de tecido gorduroso (Tabela 4), em relação à dieta controle. Em ordem de prioridade, os tecidos que se desenvolvem, de acordo com a maturidade fisiológica, são o ósseo, o muscular e o adiposo. Vários autores (Pilar, 2002; Rosa et al., 2002; Frescura et al., 2003) observaram desenvolvimento precoce do tecido ósseo, tardio do tecido adiposo e intermediário do tecido muscular. Neste estudo observou-se decréscimo na porcentagem de músculos, assim como na relação músculo:osso e músculo:gordura em função das dietas, sem afetar, no entanto, o índice de musculosidade da perna.

\section{Conclusões}

O uso de caroço de algodão proporcionou menor musculosidade de carcaça, demonstrada pela relação músculo:osso, músculo:gordura e AOL.

Nos níveis estudados, o caroço de algodão não influenciou as características e os rendimentos de cortes das carcaças de ovinos Santa Inês.

\section{Literatura Citada}

ABDUllah, A.Y.; PURCHAS, R.W.; DAVIES, A.S. Patterns of change with growth for muscularity and other composition characteristics of Southdown rams selected for high and low backfat depth. New Zealand Journal of Agricultural Research, v.41, n.3, p.367-376, 1998.

ALVES, K.S.; CARVALHO, F.F.R.; FERREIRA, M.A. et al. Níveis de energia em dietas para ovinos Santa Inês: características de carcaça e constituintes corporais. Revista Brasileira de Zootecnia, v.32, n.6, p.1927-1936, 2003 (supl. 2).

AFERRI, G.; LEME, P.R.; SILVA, S.L. et al. Desempenho e características de carcaça de novilhos alimentados com dietas contendo diferentes fontes de lipídios. Revista Brasileira de Zootecnia, v.34, p.1651-1658, 2005.

BRITO E.A. Desempenho e características de carcaças de caprinos e ovinos terminados em confinamento. Areia: Universidade Federal da Paraíba, 2002. 93p. Dissertação (Mestrado em Zootecnia) - Universidade Federal da Paraíba, 2002.

CÉZAR, M.F. Características de carcaça e adaptabilidade fisiológica de ovinos durante a fase de cria. Areia: Universidade Federal da Paraíba, 2004. 88p. Tese (Doutorado em Zootecnia) - Universidade Federal da Paraíba, 2004.

CARTAXO, F.Q. Efeitos do genótipo e da condição corporal sobre o desempenho, predição e avaliação de carcaça de cordeiros terminados em confinamento. Areia: Universidade
Federal da Paraíba, 2006. 122p. Dissertação (Mestrado em Zootecnia) - Universidade Federal da Paraíba, 2006.

EMPRESA BRASILEIRA DE PESQUISA AGROPECÚARIA EMBRAPA. Produção de carne ovina: planejamento para o mercado. Sobral: Embrapa Caprinos, 1994. (Folheto).

FORREST, J.C.A.; ABERLE, E.D.A.; HEDRICK, H.B. et al. Principles of meat science. San Francisco: W.H. Freeman, 1975. 417p.

FRESCURA, R.B.M.; PIRES, C.C.; SILVA, J.H.S. et al. Avaliação das proporções dos cortes da carcaça, características da carne e avaliação dos componentes do peso vivo de cordeiros. Revista Brasileira de Zootecnia, v.34, n.1, p.167-174, 2003.

FURUSHO-GARCIA, I.F.F.; PEREZ, J.R.O.; TEIXEIRA, J.C. Componentes de carcaça e composição de alguns cortes de cordeiros Texel x Bergamácia, Texel x Santa Inês e Santa Inês Puros, terminados em confinamento, com casca de café como parte da dieta. Revista Brasileira de Zootecnia, v.32, n.6, p.1999-2006, 2003.

GARCIA, I.F.F.; PEREZ, J.R.O.; OLIVEIRA, M.V. Características de carcaça de cordeiros Texel x Santa Inês e Santa Inês puros, terminados em confinamento com casca de café como parte da dieta. Revista Brasileira de Zootecnia, v.29, n.1, p.253-260, 2000.

HUERTA-LEIDENZ, N.O.; CROSS, H.R.; LUNT, D.K. et al. Growth, carcass traits, and fatty acid profiles of adipose tissues from steers fed whole cottonseed. Journal of Animal Science, v.69, p.3665-3672, 1991.

INSTITUTO BRASILEIRO DE GEOGRAFIA E ESTATÍSTICA IBGE. Pesquisa pecuária municipal. Disponível em: http:<www.ibge.gov.br> Acesso em: 20/4/2006.

KANDYLIS, K.; NIKOKYRIS, P.N.; DELIGIANNIS, K. Performance of growing fattening lambs fed whole cotton seed. Journal of the Science of Food and Agriculture, v.78, p.281-289, 1998.

MOLETA, J.L. Utilização de soja grão ou caroço de algodão na terminação de bovinos de corte em confinamento. In: REUNIÃO ANUAL DA SOCIEDADE BRASILEIRA DE ZOOTECNIA, 36. 1999, Porto Alegre. Anais... Porto Alegre: 1999. (CD-ROM)

MACEDO, F.A.F.; SIQUEIRA, E.R.; MARTINS, E.N. et al. Qualidade de carcaças de cordeiros Corriedale, Bergamácia $\mathrm{x}$ Corriedale e Hampshire Down x Corriedale, terminados em pastagem e confinamento. Revista Brasileira de Zootecnia, v.29, n.5, p.1520-1527, 2000.

MARTINS, R.C.; OLIVEIRA, N.; OSORIO, J.C.S. et al. Peso vivo ao abate como indicador do peso e das características quantitativas e qualitativas das carcaças em ovinos jovens da raça Ideal. Bagé: Embrapa Pecuária Sul, 2000. 29p. (Boletim de Pesquisa, 21).

MOTTA, O.S.; PIRES, C.C.; SILVA, J.H.S. et al. Avaliação da carcaça de cordeiros da raça Texel sob diferentes métodos de alimentação e pesos de abate. Ciência Rural, v.31, n.6, p.1051-1056, 2001.

MEDEIROS, S.R.; TORRES, R.A.A.; BITENCOURT, L.P. et al. Efeito do caroço de algodão na qualidade do Longissimus dorsi de bovinos de diferentes grupos genéticos terminados em confinamento. In: REUNIÃO ANUAL DA SOCIEDADE BRASILEIRA DE ZOOTECNIA, 42., 2005, Goiânia. Anais... Goiânia: Sociedade Brasileira de Zootecnia, 2005. (CD-ROM).

MEDEIROS, G.R. Efeito de níveis de concentrado sobre o desempenho, característica de carcaça e componentes não carcaça de ovinos Morada Nova em confinamento. Recife: Universidade Federal Rural de Pernambuco, 2006 108p. Tese (Doutorado em Zootecnia) - Universidade Federal Rural de Pernambuco, 2006.

NATIONAL RESEARCH COUNCIL - NRC. Nutrient requirements of sheep. 6.ed. Washington, D.C.: National Academy Press, 1989. 99p.

NGIDI, M.E.; LOERCH, S.C.; FLUHARTY, F.L. et al. Effects of calcium soaps of long-chain fatty acids on feedlot performance, carcass characteristics and ruminal metabolism of steers. Journal of Animal Science, v.68, p.2555, 1990. 
NERES, M.A.; MONTEIRO, A.L.G.; GARCIA, C.A. et al. Forma física da ração e pesos de abate nas características de carcaça de cordeiros em creep feeding. Revista Brasileira de Zootecnia, v.30, n.3, p.948-958, 2001.

OSÓRIO, J.C.S.; OLIVEIRA, N.M.; OSÓRIO, M.T.M. et al. Produção de carne em cordeiros cruza Border Leicester com ovelhas Corriedale e Ideal. Revista Brasileira de Zootecnia, v.31, n.3, p.1469-1480, 2002 (supl.).

OSORIO, J.C.S.; JARDIM, P.O.C.; PIMENTEL, M.A. et al. Produção de carne entre cordeiros castrados e não castrados. 1. Cruzas Hampshire Dow x Corriedale. Ciência Rural, v.29, n.1, p.135-138, 1999.

PURCHAS, R.W.; DAVIES, A.S.; ABDUKKAH, A.Y. An objective measure of muscularity: changes with animal growth and differences between genetic lives of southdown sheep. Meat Science, v.30, p.81-94, 1991.

PILAR, R.C.; PÉREZ, J.R.O.; SANTOS, C.L. Considerações sobre produção de cordeiros. Lavras: Universidade Federal de Lavras, 2002. 19p. (Boletim Técnico).

ROSA, G.T.; PIRES, C.C.; SILVA, J.H.S. et al. Crescimento de osso, músculo e gordura dos cortes da carcaça de cordeiros e cordeiras em diferentes métodos de alimentação. Revista Brasileira de Zootecnia, v.31, n.6, p.2283-2289, 2002.

SAINZ, R.D. Qualidade das carcaças e da carne ovina e caprina. In: REUNIÃO ANUAL DA SOCIEDADE BRASILEIRA DE ZooteCniA, 33., 1996, Fortaleza. Anais... Fortaleza: Sociedade Brasileira de Zootecnia, 1996. p.3-14.

STATISTICAL ANALYSIS SYSTEM - SAS. User's guide to statistics. Versão 8. Cary: SAS Institute, 1999. 956p.

SANTOS, C.L. Estudo do desempenho, das características de carcaça e do crescimento alométrico de cordeiros das raças Santa Inês e Bergamácia. 1999. 142p. Dissertação (Mestrado em Zootecnia) - Universidade Federal de Lavras, Lavras, 1999.

SANTOS, C.L.; PÉREZ, J.R.O.; MINIZ, J.A. et al. Desenvolvimento relativo dos tecidos ósseo, muscular, e adiposo dos cortes da carcaça de cordeiros Santa Inês. Revista Brasileira de Zootecnia, v.30, n.2, p.487-492, 2001.

SANTOS, V.C.; EZEQUIEL, J.M.B.; PINHEIRO, R.S.B. et al. Características quantitativas de carcaça de cordeiros alimentados com grãos e subprodutos da canola. In: REUNIÃO ANUAL DA
SOCIEDADE BRASILEIRA DE ZOOTECNIA, 43., 2006, João Pessoa. Anais... João Pessoa: Sociedade Brasileira de Zootecnia, 2006. (CD-ROM).

SILVA SOBRINHO, A.G. Body composition and characteristcs of carcass from lambs of different genotypes and ages at slaughter. Palmerston North: Massey University, 1999. 54p. Report (Post Doctorate in sheep Meat Production) - Massey University, 1999.

SILVA, L.F.; PIRES, C.C. Avaliações quantitativas e predição das proporções de osso músculo e gordura da carcaça de ovinos. Revista Brasileira de Zootecnia, v.29, n.4, p.1253-1260, 2000.

SILVA SOBRINHO, A.G. Aspectos quantitativos e qualitativos da produção de carne ovina. In: FEALQ (Ed.). A produção animal na visão dos brasileiros. 1.ed. Piracicaba: Fundação de Estudos Agrários Luiz de Queiroz, 2001. v.1, p.425-446.

SILVA SOBRINHO, A.G.; PURCHAS, R.N.; KADIM, I.T Musculosidade e composição da perna de ovinos de diferentes genótipos e idades de abate. Pesquisa Agropecuária Brasileira, v.40, n.11, p.1129-1134, 2005.

SILVA, S.J.; PORTUGAL, A.V. The effect of weight on growth and carcass quality of Serra of Estrela and Merino Branco lambs raised in intensive production system. Revista Portuguesa de Zootecnia, v.7, n.1, p.109-129, 2001.

SIQUEIRA, E.R.; SIMÕES, C.D.; FERNANDES, S. Efeito do genótipo e do peso sobre a produção de carne de cordeiros. Velocidade de crescimento, caracteres quantitativos da carcaça, $\mathrm{pH}$, da carne e resultado econômico. Revista Brasileira de Zootecnia, v.30, n.3, p.844-848, 2001.

SIQUEIRA, E.R.; FERNANDES, S. Efeito do genótipo sobre as medidas objetivas e subjetivas da carcaça de cordeiros terminados em confinamento. Revista Brasileira de Zootecnia, v.29, n.1, p.306-311, 2001.

URANO, F.S.; PIRES, A.V.; SUSIN, I. et al. Desempenho e características da carcaça de cordeiros confinados alimentados com grão de soja. Pesquisa Agropecuária Brasileira, v.41, n.1, p.1525-1530, 2006.

YAMAMOTO, S.M.; MACEDO, F.A.F.; MEXIA, A.A. et al. Rendimentos dos cortes e não componentes das carcaças de cordeiros terminados com dietas contendo diferentes fontes de óleo vegetal. Ciência Rural, v.34, n.6, p.1909-1913, 2004. 